\title{
Simulation optimization in inventory replenishment: A classification
}

\author{
Hamed Jalali, Inneke Van Nieuwenhuyse \\ Research Center for Operations Management \\ Department of Decision Sciences and Information Management \\ KU Leuven, Naamsestraat 69, 3000 Leuven, Belgium
}

\begin{abstract}
Simulation optimization is increasingly popular for solving complicated and mathematically intractable business problems. Focusing on academic articles published between 1998 and 2013, the present survey aims to unveil the extent to which simulation optimization has been used for solving practical inventory problems (as opposed to small, theoretical "toy problems"), and to detect any trends that might have arisen (e.g., popular topics, effective simulation optimization methods, frequently studied inventory system structures). We find that metaheuristics (especially genetic algorithms) and methods that combine several simulation optimization techniques are the most popular. The resulting categorizations provide a useful overview for researchers studying complex inventory management problems, by providing detailed information on the inventory system characteristics and the employed simulation optimization techniques, highlighting articles that involve stochastic constraints (e.g., expected fill rate constraints) or that employ a robust simulation optimization approach. Finally, in highlighting both trends and gaps in the research field, this review suggests avenues for further research.

Keywords: Inventory management, Simulation optimization, Robust simulation optimization
\end{abstract}

\section{Introduction}

The field of inventory management has attracted substantial attention in both academic literature and practice [165]. This is not surprising, as inventory represents a major cost for many businesses; e.g., the cost of holding inventory in the United States in 2006 was estimated at 300 billion dollars [150]. The goal of inventory management is to determine a replenishment policy 
(i.e., when and how much to order) that optimizes certain criteria [125], usually related to costs or service levels (though depending on the problem, other criteria might also be relevant)[147]. The number of textbooks and journal articles in this field is vast, and has shown an increasing trend $[150]$.

To find an optimal replenishment policy, many of these articles adopt analytical approaches (see [114, 136] for reviews). However, as recognized by various authors (e.g., [13, 50, 139]), practical stochastic inventory problems are often analytically intractable due to their complexity. For example, the $(\mathrm{s}, \mathrm{S})$ inventory system becomes mathematically intractable when, due to random lead times, orders cross in time [19]. In transshipment problems with more than two retailers, the retailers need to share an identical cost structure for analytical tractability to persist [106]. Likewise, in spare parts inventory management, simplifying assumptions are required for the joint optimization of maintenance and spare parts inventory policies [69].

Simulation optimization is a potentially powerful and flexible tool for solving complex optimization problems, without the need to make restrictive assumptions [105]. Simulation optimization (or sim-opt; also known as optimization via simulation or simulation-based optimization) refers to optimization of the performance of simulated systems [45, 155]; it seeks to find decision variables that will lead to optimal system performance, and it usually evaluates this performance using a simulation of the system itself [46]. In spite of the growing popularity of simulation optimization [67], Fu [54] mentions that the focus has been mostly on solving simple "toy problems" and application of sim-opt for practical problems has been limited. Standard inventory problems (such as the $(\mathrm{s}, \mathrm{S})$ system) are highly popular toy problems, designed to check the performance of newly developed sim-opt approaches (e.g., [53, 156]). For instance, the seminal paper of Bashyam and Fu [19], which was one of the first to study a stochastically constrained (s, S) system, has more than 100 citations.

Focusing on academic articles published between 1998 (the publication year of [19]) and 2013, the present survey aims to unveil to which extent subsequent sim-opt research has studied practical inventory problems (as opposed to toy problems), and to detect any trends that might have arisen (e.g., popular topics, effective sim-opt methods, frequently studied inventory system structures). The resulting categorizations provide a useful overview for researchers studying complex inventory replenishment problems: (1) they provide detailed inventory characteristics of the articles (e.g., inventory topic, number of echelons, lead time assumptions, presence of stochastic constraints); (2) they outline the employed sim-opt techniques, highlight- 
ing the articles that compare or combine sim-opt methods or that employ robust simulation optimization; and (3) they reveal the areas that require further research.

The scope of this survey is restricted to problem settings in which the key decision variables relate to the replenishment policy (i.e., when and how much to order) of input/output inventories at the supply chain level. Input inventories get replenished by ordering from outside suppliers (either within the same stage or another stage in the supply chain); an output inventory, instead, delivers goods to another player (at the same or the next stage). We thus do not consider workin-process inventories within a given stage.

Table 1: Details of the search method

\begin{tabular}{cccccc}
\hline Database & Simulation & Optimization & Inventory & Quartiles & Year \\
\hline Web of Science & Title or Topic & Title or Topic & Topic & Q1 or Q2 & $1998-2013$ \\
ScienceDirect & Title, abstract or keywords & Title, abstract or keywords & Full text & Q1 or Q2 & $1998-2013$ \\
INFORMS & Keywords & Full text & Full text & Q1 or Q2 & $1998-2013$ \\
TaylorEFrancis & Keywords & Full text & Full text & Q1 or Q2 & $1998-2013$ \\
\hline
\end{tabular}

This survey includes 102 relevant papers that are representative of this research field. As shown in Table 1, these articles represent the results of a search in:

- The SCI Expanded index of the Web of Science. This search resulted in 2304 articles, 92 of which were relevant.

- ScienceDirect: this search resulted in 534 articles, 63 of which were relevant; 3 of these were not in the Web of Science results.

- INFORMS: this search resulted in 68 articles, 10 of which were relevant; 4 of these were new comparing to the Web of Science results.

- Taylor\&Francis: this search resulted in 139 articles, 9 of which were relevant; 3 of these were new comparing to the Web of Science results.

We considered articles published in all journals that are ranked in the Q1 or Q2 quartiles based on the impact factor, for at least one of their subject categories (according to the Journal Citation Reports (JCR) published by Thomson Reuters; http://wokinfo.com/products_tools/analytical/jcr/).

We classify the articles into two categories: domain and methodology focused. A contribution in the domain focused category seeks as its main purpose to tackle an inventory problem (with 
the help of simulation optimization). Because they aim to solve practical inventory problems, the domain focused articles tend to relax the stringent, unrealistic assumptions that often occur in (analytical) inventory management papers, then solve the resulting complex problem using simulation optimization. Methodology focused articles instead seek to develop sim-opt techniques and usually use simple inventory problems (so-called toy problems) to illustrate the performance of their proposed method. As shown in Table 2, most of the surveyed articles were published in European Journal of Operational Research, International Journal of Production Economics, or International Journal of Production Research.

Table 2: List of Journals

\begin{tabular}{|c|c|c|c|}
\hline Journal & $\begin{array}{l}\text { Methodology } \\
\text { focused }\end{array}$ & $\begin{array}{l}\text { Domain } \\
\text { focused }\end{array}$ & Total \\
\hline European Journal of Operational Research & 6 & 10 & 16 \\
\hline International Journal of Production Economics & 1 & 11 & 12 \\
\hline International Journal of Production Research & 0 & 11 & 11 \\
\hline Computers \& Operations Research & 3 & 5 & 8 \\
\hline Computers $\&$ Industrial Engineering & 3 & 5 & 8 \\
\hline IIE Transactions & 5 & 3 & 8 \\
\hline Operations Research & 2 & 3 & 5 \\
\hline INFORMS Journal on Computing & 3 & 0 & 3 \\
\hline Industrial \& Engineering Chemistry Research & 0 & 3 & 3 \\
\hline Applied Mathematical Modelling & 0 & 3 & 3 \\
\hline Knowledge Based Systems & 0 & 2 & 2 \\
\hline Omega & 0 & 2 & 2 \\
\hline Expert Systems with Applications & 1 & 1 & 2 \\
\hline Management Science & 2 & 0 & 2 \\
\hline International Journal of Computer Integrated Manufacturing & 1 & 1 & 2 \\
\hline Simulation Modeling Practice and Theory & 2 & 0 & 2 \\
\hline Production and Operations Management & 0 & 1 & 1 \\
\hline Annals of Operations Research & 1 & 0 & 1 \\
\hline Journal of the Operational Research Society & 1 & 0 & 1 \\
\hline Fuzzy Optimization and Decision Making & 0 & 1 & 1 \\
\hline Decision Support Systems & 1 & 0 & 1 \\
\hline Transportation Research Part E: Logistics and Transportation Review & 0 & 1 & 1 \\
\hline Applied mathematics and computation & 1 & 0 & 1 \\
\hline Computers $\&$ Mathematics with Applications & 1 & 0 & 1 \\
\hline Mathematical and Computer Modelling & 0 & 1 & 1 \\
\hline Applied Soft Computing & 0 & 1 & 1 \\
\hline Computers $\&$ Chemical Engineering & 1 & 0 & 1 \\
\hline Engineering Optimization & 1 & 0 & 1 \\
\hline The International Journal of Advanced Manufacturing Technology & 0 & 1 & 1 \\
\hline
\end{tabular}


The remainder of this review is organized as follows: Section 2 gives a brief overview of simulation optimization techniques and provides the required terminology and acronyms. Section 3 categorizes the articles according to their focus. In Section 4 we categorize the articles according to the characteristics of the inventory problem, then in Section 5 we categorize them according to the simulation optimization method they apply (the majority of the reviewed articles employ metaheuristics, especially genetic algorithms, or methods that combine several sim-opt techniques). Finally, Section 6 highlights the conclusions and promising areas for further research.

\section{Simulation optimization techniques}

In this section, we give a brief overview of simulation optimization techniques. Comprehensive surveys are available in $[52,54,135]$; more recent reviews appear in [57, 67]. For an in-depth discussion of popular sim-opt methods we refer to the recent handbook by $\mathrm{Fu}$ [56]. In its most basic form, the simulation optimization problem aims to find the values of the decision variables that minimize a given objective function:

$$
\min _{\boldsymbol{\theta} \in \Phi} J(\boldsymbol{\theta})
$$

where $\boldsymbol{\theta}$ represents the vector of decision variables, and $\Phi$ is the constraint set, which is deterministic and known. Assuming that the objective function cannot be analytically expressed, it must be estimated through simulation, leading to a problem of the form [57, 109]:

$$
\min _{\boldsymbol{\theta} \in \Phi} J(\boldsymbol{\theta})=E[Y(\boldsymbol{\theta}, \boldsymbol{\omega})]
$$

where $\boldsymbol{\omega}$ represents a set of pseudorandom numbers, and $Y$ is a random response, computed through simulation. The value of the objective function $J$ under the design scenario specified by $\boldsymbol{\theta}$ is estimated by $n$ simulation runs at this design scenario $[18,89]$ :

$$
\hat{J}_{n}(\boldsymbol{\theta})=\sum_{i=1}^{n} Y\left(\boldsymbol{\theta}, \omega_{i}\right) / n .
$$

The number of simulation replications $n$ used in the estimation is a key determinant of the computational cost for simulation optimization techniques [54]. As Banks et al. [16] explain, Problem (2) is difficult, because the exact value of the objective function remains unknown; we only have an estimate. Specifically, given two solutions $\boldsymbol{\theta}_{1}$ and $\boldsymbol{\theta}_{2}$ and simulation estimates 
of objective functions $\hat{J}\left(\boldsymbol{\theta}_{1}\right)$ and $\hat{J}\left(\boldsymbol{\theta}_{2}\right)$, the fact that $\hat{J}\left(\boldsymbol{\theta}_{1}\right)<\hat{J}\left(\boldsymbol{\theta}_{2}\right)$ does not guarantee that $J\left(\boldsymbol{\theta}_{1}\right)<J\left(\boldsymbol{\theta}_{2}\right)$ [104]. In fact, the stochastic nature of the estimate is one of the most important issues to be taken into account when designing a simulation optimization technique [54].

The problem may also feature constraints that must be evaluated by simulation; these are commonly referred to as stochastic constraints (deterministic constraints are reflected in the set $\Phi$, e.g., $s<S$ in $(s, S)$ inventory problems; such deterministic constraints are easier to satisfy). Stochastic constraints frequently arise in settings in which one simulation response must be minimized (maximized), while other responses need to be smaller or larger than a threshold $[54,57]$. Problem (2) then can be extended as follows $[8,108]$ :

$\min _{\boldsymbol{\theta} \in \Phi} J(\boldsymbol{\theta})=E\left[Y_{0}(\boldsymbol{\theta}, \boldsymbol{\omega})\right]$

subject to $E\left[Y_{j}(\boldsymbol{\theta}, \boldsymbol{\omega})\right] \geq a_{j}$ for $j=1, \ldots, r-1$,

where $Y_{i}(i=0, \ldots, r-1)$ is a random response evaluated through simulation, and $a_{j}$ is the deterministic threshold for constraint $j$. In rare cases, the objective function may be deterministic; then at least one of the constraints must be estimated through simulation to have a simulation optimization problem (e.g., [139]). Research dedicated to solving Problem (4) is still relatively limited $[20,54,57,99,109]$. Two main approaches exist. In the first, the constraints get incorporated into the objective function, using penalty functions or Lagrange multipliers [54, 99], which essentially removes the stochastic constraint and facilitates a solution through a standard simulation optimization technique. Examples of this approach include [96], where a penalty function integrates the constraints into the objective function, and the problem then can be solved using a random search, and [99] which uses Lagrange multipliers to handle constraints on the fill rate in an $(\mathrm{R}, \mathrm{s}, \mathrm{S})$ inventory problem (see also $[27,108,149])$. The second approach instead tries to modify the simulation optimization technique in a way that enables it to handle stochastic constraints explicitly. In the remainder of this review, we specifically highlight the articles that use the latter approach.

The different sim-opt methods can be categorized according to whether the decision variables are discrete or continuous; Figure 1 (adapted from [18, 70]) gives an overview. When decision variables are discrete and the feasible set is finite and small (at most a few hundred feasible solutions, [155]), both multiple comparisons and ranking and selection (R\&S) can be used. The main idea of multiple comparisons is to run several simulation replications at each design point 


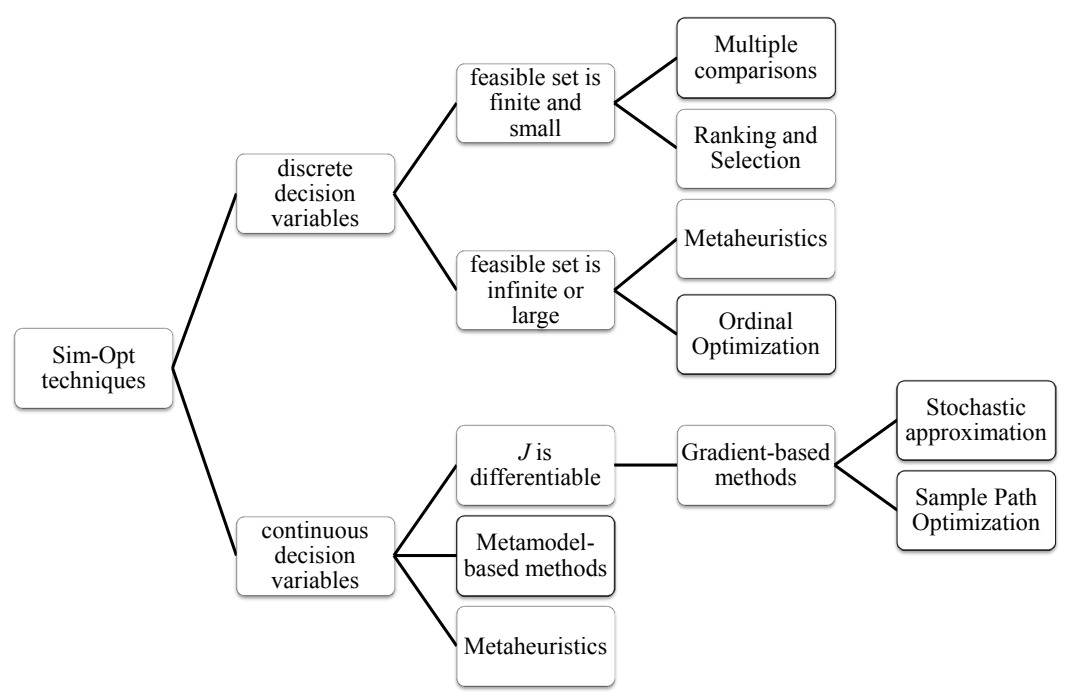

Figure 1: Categorization of sim-opt techniques

(at each $\boldsymbol{\theta}$ ) to make inferences about the simulation response, using confidence intervals [52]. The most popular approach in multiple comparisons is the multiple comparison with the best (MCB) $[52,60,68,130]$. Unlike multiple comparisons, R\&S can handle problems with stochastic constraints explicitly (see $[20,139])$. Although R\&S has many versions, the two main approaches are the indifference zone and subset selection $[52,130]$. In the indifference zone approach, we try to find a solution $\tilde{\boldsymbol{\theta}}$ with an objective value that differs from the optimal solution $J\left(\boldsymbol{\theta}^{*}\right)$ by at most a small amount $\delta$, with a probability of at least $P^{*}[52]$. The main goal in the subset selection approach is to select a subset consisting of at most $m$ designs such that it contains the best design with a probability of at least $P^{*}[135]$. Comprehensive surveys of R\&S can be found in $[40,79]$. When the feasible set is very large (or even infinite), metaheuristic methods are popular [67]: examples include genetic algorithms, tabu search, simulated annealing, and particle swarm optimization. Although these methods are mainly used with discrete decision variables, they also could be used in a continuous case [54] (e.g., [6]). Excellent reviews of metaheuristic methods can be found in [5, 104]. Recently, Tsai and Fu [138] modified genetic algorithms for handling a single stochastic constraint. Ordinal optimization is the other, probably less popular approach for solving large discrete problems. Instead of looking for the global optimum, this method seeks to find one of the top- $n$ solutions by sampling $k$ solutions and trying to select the best among them [130]. As highlighted in [155], "The critical decision is choosing $k$ such that at least one of the simulated solutions is a top- $n$ solution". More information on ordinal 
optimization can be found in [64]. Li et al. [95] modified this method to handle stochastic constraints.

When the decision variables are continuous, most discrete simulation optimization techniques become unsuitable, because the number of feasible solutions is infinite. As shown in Figure 1, gradient-based methods (e.g., stochastic approximation, sample path optimization) are appropriate when the objective function is differentiable (the differentiability and continuity of the objective function of Problem (2) can be checked by coupling theory, see [77]). Stochastic approximation is a natural adaptation of steepest-descent algorithms in deterministic nonlinear optimization; sample path optimization tries to approximate Problem (2) by a deterministic optimization problem, and then exploit deterministic optimization methods [4]. Both methods require simulation to estimate the gradient of the objective function [4], such as by using finite differences, simultaneous perturbations, likelihood ratio, or perturbation analysis (especially infinitesimal perturbation analysis or IPA). Finite differences and simultaneous perturbations require no knowledge about the simulation model and are applicable to any simulated system [59]; the advantage of the latter (known as simultaneous perturbations stochastic approximation or SPSA, proposed by Spall [127]) is that it only needs 2 simulation runs to estimate the gradient regardless of the dimension of the problem, making it very efficient for high dimensional problems $[67,128]$. Likelihood ratio and perturbation analysis, on the other hand, are not always applicable but usually provide unbiased estimators for the gradient; [55] provides a comprehensive survey. Both stochastic approximation and sample path optimization can handle stochastic constraints: see [19] and [4, 78], respectively. More information about stochastic approximation can be found in [3, 52], for sample path optimization refer to [78, 119]. Metamodel and metaheuristic methods, in contrast, do not require differentiability of the objective function. Metamodel-based approaches apply the optimization to a metamodel that captures the relation between the decision variables and the simulation output [80], providing an approximating function for $J(\boldsymbol{\theta})$ that is inexpensive to compute [18]. After obtaining the metamodel, it is possible to employ techniques developed for deterministic optimization to find the optimal solution [17]. Local metamodels (such as RSM: $[18,80]$ ) commonly determine a search direction for the optimization; for global metamodels, we find neural networks, kriging models, or radial basis functions usually employed (see [18] for an interesting review of these metamodelling techniques). Both global and local metamodels can be used to solve Problem (4): see Angün et al. [9] for an extension of RSM (referred to as generalized RSM, or GRSM; also 
Table 3: List of sim-opt methods and their associated acronyms

\begin{tabular}{ll}
\hline Approach & Type \\
\hline Metaheuristics (MH) & Genetic algorithms (GA) \\
& Particle swarm optimization (PSO) \\
& Simulated annealing (SA) \\
& Other metaheuristic methods (MH-O) \\
\hline Metamodel-based methods (MM) & Neural networks (NN) \\
& Response surface methodology (RSM) \\
\hline Stochastic approximations (STA) & Kriging (KR) \\
\hline Sample path optimization (SPO) & Other Metamodel-based methods (MM-O) \\
\hline Multiple comparisons (MC) & \\
\hline Ranking and selection (R\&S) & \\
\hline Other & \\
\hline
\end{tabular}

see [81]), Kleijnen et al. [82] and Biles et al. [28] for an illustration using kriging, and Nezhad and Mahlooji [103] for an application of neural networks.

Table 3 lists the acronyms used throughout the current article to refer to the different simulation optimization methods. The table follows the outline provided in Figure 1, adding two extra categories: Hybrid (i.e., methods that combine different sim-opt approaches) and Other (approaches that do not belong to any of the other categories).

\section{Categorization based on domain/methodology focus}

Table 4 offers an overview of the surveyed articles, classified as either domain or methodology focused (defined in Section 1). The asterisk $\left(^{*}\right)$ is used to denote articles that study settings involving explicit stochastic constraints: most of the papers (7 of 12) that deal with stochastic constraints belong to the methodology focused category. As shown in Table 5, the stochastic constraint in most of these articles is related to customer service (and especially expected fill rate). In $[44,45]$, the variance of the objective function appears as a stochastic constraint: these articles belong to the set of robust sim-opt papers; see Table 12 . 
Table 4: Categorization of surveyed papers according to focus

\begin{tabular}{ll}
\hline Focus & References \\
\hline Domain & $11,12,13,14,15^{*}, 21^{*}, 23,24,29,30,31,37,38,39,43,47,48,49^{*}, 50,51,62,63$, \\
& $65,69,72,75,76,84,85,87,88,89,97,100,101,106,107,112,113,115,117,120$, \\
& $121,122,124,126,129,131,132,133,134,137,139^{*}, 140,141,142,144,145,146$, \\
& $152^{*}, 153,159,161,162,163,164$ \\
\hline Methodology & $1,2,7^{*}, 19^{*}, 22,32^{*}, 33,34,35,36,41,42,44^{*}, 45^{*}, 61,66,73,74,82^{*}, 83^{*}, 90,91,93$, \\
& $94,98,99,102,111,116,118,123,143,151,154,155,160$
\end{tabular}

*Note: The entries with asterisk are stochastically constrained

As shown in Figure 2, the majority of articles published between 1998 and 2013 are domain focused; we thus find a clear indication that simulation optimization is increasingly used to tackle practical inventory problems. The shift from methodology to domain focused articles is most evident as from 2004. The figure also illustrates that the popularity of sim-opt in inventory management research has increased significantly since 2004 .

Table 5: Type of constraints in stochastically constrained articles

\begin{tabular}{lll}
\hline Type & References \\
\hline Customer service & expected fill rate & $7,15,19,49,82,83$ \\
& expected response time & 139 \\
& other & 21 \\
\hline Variance of objective function & 44,45 \\
\hline Expected holding cost & 32 \\
\hline Expected inventory level & 152 \\
\hline
\end{tabular}

\section{Categorization based on inventory problem characteristics}

In this section, we categorize the surveyed articles according to the characteristics of the inventory problem studied. We adopt the following criteria [148] :

- Echelons: indicates whether the inventory problem is Single, Dual, or Multi-echelon. A supply chain stage only counts as an echelon when replenishment decisions (e.g., reorder point, order-up-to level) are required for players at that specific stage; when no such 


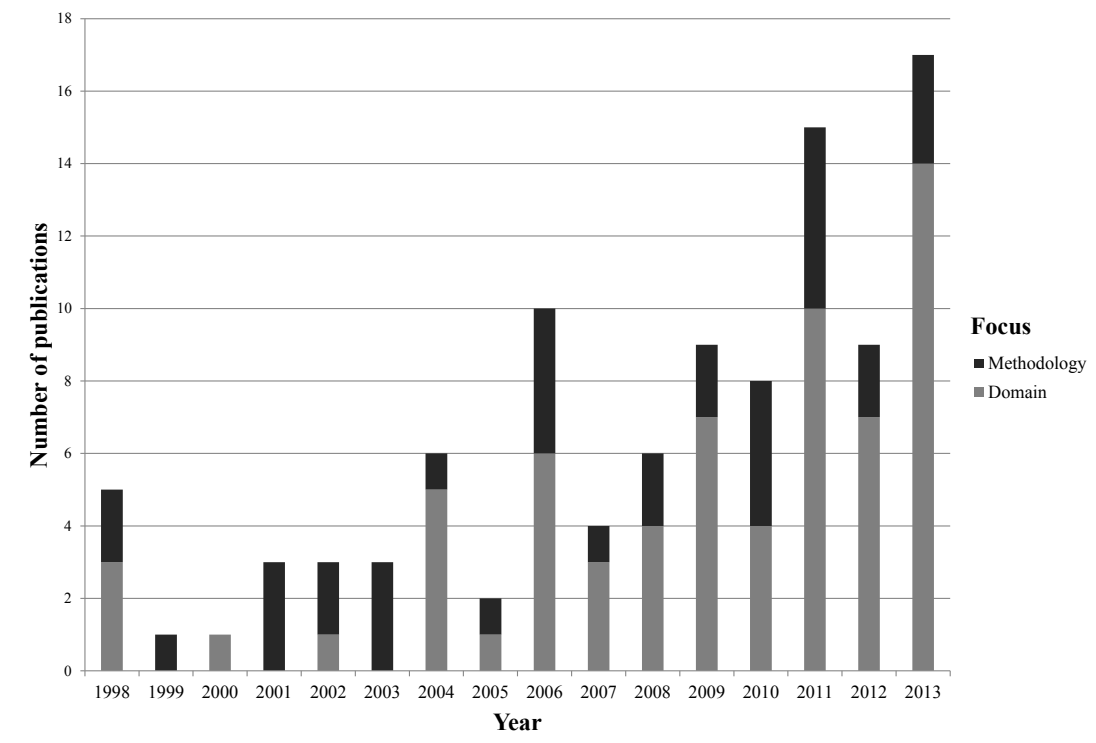

Figure 2: Number of domain and methodology focused articles published in each year decisions are required, the stage does not count as an echelon.

- Items: indicates a Single- or Multi-item problem.

- Horizon: the planing horizon of the problem, either single period, finite, infinite, or irrelevant $(I R)$.

- Lead time: the assumptions about the replenishment lead time at each echelon. Echelons are separated by arrows: for a two-echelon system, we have lead time upstream echelon $\rightarrow$ lead time downstream echelon. For instance the notation $D T \rightarrow D T$ denotes that both echelons have deterministic, while $S T \rightarrow S T$ implies that both have stochastic lead times. Other notations are irrelevant $(I R)$, negligible $(N G)$, or not specified $(N S)$. For multiechelon systems, the notation " $\rightarrow \cdots$ " states that the lead time is the same for all echelons, for instance the notation $S T \rightarrow \cdots S T$ denotes a system where all echelons have stochastic lead times.

- Policy: the replenishment policy used at any given echelon [148]. Echelons are separated by arrows: for two echelon systems we again have policy of upstream echelon $\rightarrow$ policy of downstream echelon. For multi-echelon systems, the notation " $\rightarrow \cdots$ " states that the policy is the same for all echelons:

- $N V$ : traditional single-period newsvendor policy, with optimal order quantity deter- 
mined before the start of the sales period.

- $(R, S)$ : the inventory position is checked every $R$ periods, after which an order brings the inventory position back to the order-up-to level $S$.

- $(R, s, S)$ : the inventory position is checked every $R$ periods; only when it is below a reorder point $s$, an order is sent to bring the inventory position back to the orderup-to level $S$.

- $(r, Q)$ : the inventory position is reviewed continuously; as soon as it falls below the reorder point $r$, an order of size $Q$ is generated.

- $(s, n Q)$ : the inventory position is reviewed continuously; as soon as it drops below the reorder point $s$, an order is placed equal to the smallest multiple of $Q$ that raises the inventory position above $s$.

- $(s, S)$ : same as $(\mathrm{R}, \mathrm{s}, \mathrm{S})$, but the inventory position is reviewed continuously.

- $(S-1, S)$ : The inventory position is reviewed continuously, and each customer order triggers a replenishment order of one unit.

- other: any replenishment policy that does not fit into one of these policies.

- NS: not specified.

For instance $(R, S) \rightarrow(R, S)$ denotes that both echelons use the $(R, S)$ inventory policy and $(s, S) \rightarrow \cdots(s, S)$ indicates a multi-echelon system where all echelons employ the $(s, S)$ policy.

For the domain focused articles, we distinguish the following main inventory topics (each having at least three reviewed articles): spare parts inventory management, transshipment problem, substitution problems, inventory centralization benefits, and imperfect quality items (where the percentage of defective items in each replenishment lot is random and inspection is needed). Table 6 presents the categorization of the domain focused articles that belong to these main topics. The remaining articles are categorized in Table 7; these focus on a multitude of other topics (e.g., manufacturing and remanufacturing, assemble to order systems). Finally, Table 8 categorizes the methodology focused contributions. For ease of reference, the tables also show the sim-opt approach used (as outlined in Table 3). 
Table 6: Categorization of domain focused articles (main topics) according to the inventory problem characteristics

\begin{tabular}{|c|c|c|c|c|c|c|c|}
\hline Topic & Echelons & Items & Horizon & Lead time & Policy & Sim-opt & References \\
\hline \multirow[t]{7}{*}{ Spare parts } & Single & Single & Infinite & DT & $(\mathrm{R}, \mathrm{s}, \mathrm{S})$ & $\mathrm{MH}$ & 144 \\
\hline & & & & $\mathrm{ST}$ & $(\mathrm{r}, \mathrm{Q})$ & $\mathrm{MM}$ & 24 \\
\hline & & & & & $(\mathrm{s}, \mathrm{S})$ & other & 121 \\
\hline & & Multi & Finite & DT & $(\mathrm{s}, \mathrm{S})$ & $\mathrm{MH}$ & 100 \\
\hline & & & Infinite & $\mathrm{ST}$ & $(\mathrm{S}-1, \mathrm{~S})$ & Hybrid & $139 *$ \\
\hline & & & & & $(\mathrm{s}, \mathrm{S})$ & $\mathrm{MH}$ & 69 \\
\hline & Dual & Single & Infinite & $\mathrm{ST} \rightarrow \mathrm{ST}$ & $(\mathrm{S}-1, \mathrm{~S}) \rightarrow(\mathrm{S}-1, \mathrm{~S})$ & $\mathrm{MH}$ & 141 \\
\hline \multirow[t]{8}{*}{ Transshipment } & Single & Single & Finite & DT & $(\mathrm{R}, \mathrm{S})$ & Hybrid & 162 \\
\hline & & & & & $(\mathrm{R}, \mathrm{s}, \mathrm{S})$ & $\mathrm{MH}$ & 65 \\
\hline & & & Infinite & NG & $(\mathrm{R}, \mathrm{S})$ & Hybrid & $63,106,107$ \\
\hline & & & & DT & $(\mathrm{R}, \mathrm{s}, \mathrm{S})$ & Hybrid & 161 \\
\hline & & & & $\mathrm{ST}$ & $(\mathrm{R}, \mathrm{s}, \mathrm{S})$ & $\mathrm{MH}$ & 43 \\
\hline & Dual & Single & Finite & $\mathrm{DT} \rightarrow \mathrm{DT}$ & $(\mathrm{R}, \mathrm{s}, \mathrm{S}) \rightarrow(\mathrm{R}, \mathrm{s}, \mathrm{S})$ & Hybrid & 137 \\
\hline & & & Infinite & $\mathrm{DT} \rightarrow \mathrm{DT}$ & $(\mathrm{R}, \mathrm{S}) \rightarrow(\mathrm{R}, \mathrm{S})$ & $\mathrm{MM}$ & 23 \\
\hline & & & & $\mathrm{ST} \rightarrow \mathrm{ST}$ & $(\mathrm{S}-1, \mathrm{~S}) \rightarrow(\mathrm{S}-1, \mathrm{~S})$ & $\mathrm{MH}$ & 141 \\
\hline \multirow[t]{5}{*}{ Centralization } & Single & Multi & Finite & DT & other & $\mathrm{MH}$ & 37 \\
\hline & Dual & Single & Finite & $\mathrm{DT} \rightarrow \mathrm{DT}$ & $(\mathrm{R}, \mathrm{S}) \rightarrow(\mathrm{R}, \mathrm{S})$ & Hybrid & $49^{*}$ \\
\hline & & & & & $(\mathrm{R}, \mathrm{s}, \mathrm{S}) \rightarrow(\mathrm{R}, \mathrm{s}, \mathrm{S})$ & $\mathrm{MH}$ & 50 \\
\hline & Multi & Single & Infinite & $\mathrm{DT} \rightarrow \cdots \mathrm{DT}$ & $(\mathrm{R}, \mathrm{S}) \rightarrow \cdots(\mathrm{R}, \mathrm{S})$ & $\mathrm{MH}$ & 101 \\
\hline & & & & $\mathrm{ST} \rightarrow \cdots \mathrm{ST}$ & $(\mathrm{r}, \mathrm{Q}) \rightarrow \cdots(\mathrm{r}, \mathrm{Q})$ & $\mathrm{MH}$ & 84 \\
\hline \multirow[t]{4}{*}{ Imperfect quality } & Single & Single & Infinite & NG & $(\mathrm{r}, \mathrm{Q})$ & $\mathrm{MH}$ & 146 \\
\hline & & & & & & MM & 31 \\
\hline & & & & & & other & 145 \\
\hline & & Multi & Infinite & DT & other & $\mathrm{MH}$ & 126 \\
\hline \multirow[t]{3}{*}{ Substitution } & Single & Multi & Single & IR & NV & $\mathrm{MH}$ & 140 \\
\hline & & & & & & STA & 117 \\
\hline & & & & & & Hybrid & $21^{*}$ \\
\hline
\end{tabular}

*Note: The entries with asterisk are stochastically constrained.

Table 6 reveals clear distinctions regarding the inventory policies studied. While spare parts problems, transshipment problems and centralization problems are almost exclusively studied using order-up-to policies, imperfect quality problems tend to assume a fixed order quantity, and substitution problems are limited to (single-period) newsvendor settings. Table 9 provides further details on the transshipment papers; following [110], we include the type of transshipment, the pooling policy, the number of depots or retailers and the presence of non-identical depots (i.e., depots/retailers that differ in terms of cost parameters), fixed ordering cost, and/or a 
transshipment lead time. Within an emergency transshipment approach, a firm that confronts a stock-out can ask another firm at the same echelon to ship inventory; transshipment thus occurs after demand is observed but before it is satisfied [106]. In contrast, a preventive transshipment redistributes stock before the demand is realized, to decrease the chances of a stock-out [137]. In the complete pooling policy, a stocking location can ship its entire on-hand inventory to another location; in the partial policy, stocking locations "share only a certain amount of their inventory for transshipment" [106].

As is evident from Table 9, most surveyed transshipment articles consider emergency transshipment, combined with a complete pooling policy. Herer et al. [63] were among the first to study transshipment problems with an arbitrary number of retailers that differ in terms of the cost parameters (a setting that is not analytically tractable [106]). Their problem has been extended in several ways by subsequent authors: Özdemir et al. [106] added limited transportation capacity between retailers and showed that the sim-opt method of [63] can be easily modified for this setting, Hochmuth and Köchel [65] studied more flexible and realistic transshipment policies, Yücesan and Gong [162] relaxed the assumption of a negligible replenishment lead time, and Özdemir et al. [107] took supplier capacity into account (an extension that complicates the sample path optimization of [63]). Although Tlili et al. [137] assume only 2 identical retailers, the limited supplier capacity and presence of replenishment lead time make their problem difficult. Finally, in preventive transshipment articles, Young Yun et al. [161] optimize the replenishment policies of a single depot while Dang et al. [43] extend this problem to $\mathrm{N}$ depots.

Likewise, Table 10 details the characteristics of the articles that consider spare parts inventory management. As mentioned by Lynch et al. [100], spare parts inventory management is a special case of general inventory management, typically characterized by (1) very high stockout costs (due to the high cost associated with machine downtime), (2) erratic and low volume demand, and (3) considerable holding costs, because spare parts are usually quite expensive. The availability of spare parts is a necessary requirement for efficient and effective maintenance, and accordingly, spare parts inventory management has received considerable research attention. Maintenance can be corrective or preventive: Corrective maintenance restores the machine to a specified condition in case of a failure [100], whereas preventive maintenance refers to actions taken before the failure to maintain an operating machine in a desired condition [144]. Preventive maintenance can be time-based (also known as scheduled maintenance), with maintenance done at certain intervals, irrespective of the system condition, or condition-based, such that 
Table 7: Categorization of domain focused articles (other topics), according to the inventory problem characteristics

\begin{tabular}{|c|c|c|c|c|c|c|}
\hline Echelons & Items & Horizon & Lead time & Policy & Sim-opt & References \\
\hline \multirow[t]{30}{*}{ Single } & Single & Single & NG & NV & $\mathrm{MC}$ & 14 \\
\hline & & Finite & NG & $(\mathrm{R}, \mathrm{S})$ & $\mathrm{MH}$ & 38 \\
\hline & & & & other & MM \& Hybrid & $152^{*}$ \\
\hline & & & DT & $(\mathrm{R}, \mathrm{S})$ & $\mathrm{MH}$ & 159,164 \\
\hline & & & & $(\mathrm{R}, \mathrm{s}, \mathrm{S})$ & MM \& Hybrid & 124 \\
\hline & & & & $(\mathrm{r}, \mathrm{Q})$ & $\mathrm{MH}$ & 88 \\
\hline & & & & other & $\mathrm{SPO}$ & 51 \\
\hline & & & $\mathrm{ST}$ & other & STA & 30 \\
\hline & & Infinite & NG & $(\mathrm{r}, \mathrm{Q})$ & $\mathrm{MH}$ & 97 \\
\hline & & & DT & $(\mathrm{R}, \mathrm{S})$ & other & 142 \\
\hline & & & & $(\mathrm{r}, \mathrm{Q})$ & $\mathrm{MH}$ & 39 \\
\hline & & & & & MH \& Hybrid & 76 \\
\hline & & & & $(\mathrm{s}, \mathrm{S})$ & Hybrid & 47 \\
\hline & & & $\mathrm{ST}$ & $(\mathrm{R}, \mathrm{S})$ & other & 153 \\
\hline & & & & $(\mathrm{S}-1, \mathrm{~S})$ & $\mathrm{MH}$ & 89 \\
\hline & & & & & $\mathrm{MC}$ & 120 \\
\hline & & & & other & Hybrid & 163 \\
\hline & & Finite/Infinite & NG & $(\mathrm{R}, \mathrm{S})$ & STA & 75 \\
\hline & Multi & Single & IR & NV & $\mathrm{MH}$ & 131 \\
\hline & & Finite & DT & $(\mathrm{R}, \mathrm{s}, \mathrm{S})$ & MM & 122 \\
\hline & & & & $(\mathrm{r}, \mathrm{Q})$ & $\mathrm{MH}$ & 133 \\
\hline & & & & & Hybrid & $15^{*}$ \\
\hline & & Infinite & NG & $(\mathrm{R}, \mathrm{S})$ & $\mathrm{MH}$ & 132 \\
\hline & & & DT & $(\mathrm{R}, \mathrm{S})$ & $\mathrm{MH}$ & 62 \\
\hline & & & & & STA & 11 \\
\hline & & & & $(\mathrm{r}, \mathrm{Q})$ & $\mathrm{MH}$ & 72 \\
\hline & & & & $(\mathrm{s}, \mathrm{nQ}) /(\mathrm{s}, \mathrm{S})$ & $\mathrm{MH}$ & 85 \\
\hline & & & $\mathrm{ST}$ & $(\mathrm{r}, \mathrm{Q})$ & $\mathrm{MH}$ & 134 \\
\hline & & & & $(\mathrm{S}-1, \mathrm{~S})$ & MM & 13 \\
\hline & & & & other & other & 87 \\
\hline \multirow[t]{4}{*}{ Dual } & Single & Infinite & $\mathrm{DT} \rightarrow \mathrm{DT} / \mathrm{ST}$ & $(\mathrm{S}-1, \mathrm{~S}) \rightarrow(\mathrm{S}-1, \mathrm{~S})$ & Hybrid & 12 \\
\hline & & & $\mathrm{ST} \rightarrow \mathrm{ST}$ & $(\mathrm{r}, \mathrm{Q}) \rightarrow(\mathrm{r}, \mathrm{Q})$ & other & 29 \\
\hline & Multi & Finite & $\mathrm{DT} \rightarrow \mathrm{DT}$ & $(\mathrm{R}, \mathrm{S}) /$ other $\rightarrow(\mathrm{R}, \mathrm{S}) /$ other & $\mathrm{MH}$ & 129 \\
\hline & & Infinite & $\mathrm{ST} \rightarrow \mathrm{ST}$ & $(\mathrm{r}, \mathrm{Q}) /(\mathrm{s}, \mathrm{S}) \rightarrow(\mathrm{r}, \mathrm{Q}) /(\mathrm{s}, \mathrm{S})$ & $\mathrm{MH}$ & 48 \\
\hline \multirow[t]{2}{*}{ Multi } & Single & Finite & $\mathrm{NG} \rightarrow \cdots \mathrm{NG}$ & other $\rightarrow \cdots$ other & other & 115 \\
\hline & Multi & Infinite & $\mathrm{DT} \rightarrow \cdots \mathrm{DT}$ & $(\mathrm{s}, \mathrm{S}) \rightarrow \cdots(\mathrm{s}, \mathrm{S})$ & $\mathrm{MC}$ & 112,113 \\
\hline
\end{tabular}

*Note: The entries with asterisk are stochastically constrained. 
Table 8: Categorization of methodology focused articles, according to the inventory problem characteristics

\begin{tabular}{|c|c|c|c|c|c|c|c|}
\hline Topic & Echelons & Items & Horizon & Lead time & Policy & Sim-opt & References \\
\hline Substitution & Single & Multi & Single & IR & NV & $\mathrm{MH}$ & 155 \\
\hline \multirow[t]{31}{*}{ Other } & Single & Single & IR & IR & other & Hybrid & 116 \\
\hline & & & Finite & NG & $(\mathrm{R}, \mathrm{s}, \mathrm{S})$ & STA & 99 \\
\hline & & & & & & $R \& S$ & $34,41,42$ \\
\hline & & & & $\mathrm{ST}$ & & $\mathrm{R} \& \mathrm{~S}$ & 33 \\
\hline & & & Infinite & NG & $(\mathrm{R}, \mathrm{s}, \mathrm{S})$ & MH \& Hybrid & 35,36 \\
\hline & & & & & & $\mathrm{MM}$ & 154 \\
\hline & & & & & & STA \& Hybrid & 73,74 \\
\hline & & & & & & Hybrid & 1,111 \\
\hline & & & & & $(\mathrm{r}, \mathrm{Q})$ & MM & $44^{*}, 45^{*}$ \\
\hline & & & & DT & $(\mathrm{r}, \mathrm{Q})$ & $\mathrm{MH}$ & 98 \\
\hline & & & & ST & $(\mathrm{R}, \mathrm{s}, \mathrm{S})$ & $\mathrm{MH}$ & 2 \\
\hline & & & & & & MM & $7^{*}, 32^{*}$ \\
\hline & & & & & & MM \& Hybrid & $82^{*}$ \\
\hline & & & & & & STA & $19^{*}$ \\
\hline & & & & & $(\mathrm{r}, \mathrm{Q})$ & $\mathrm{MH}$ & 90 \\
\hline & & & & & & MM & 61 \\
\hline & & & & & $(\mathrm{s}, \mathrm{S})$ & $\mathrm{MH}$ & 22 \\
\hline & & & & & & MM \& & e.* \\
\hline & & & & & & STA \& Hybrid & 00 \\
\hline & & & & & Other & STA & 102 \\
\hline & & & & NG/ST & $(\mathrm{r}, \mathrm{Q})$ & other & 118 \\
\hline & & Multi & Single & IR & NV & SPO & 93 \\
\hline & & & Infinite & $\mathrm{DT}$ & $(\mathrm{R}, \mathrm{s}, \mathrm{S})$ & $\mathrm{MH}$ & 151 \\
\hline & & & & $\mathrm{ST}$ & $(\mathrm{S}-1, \mathrm{~S})$ & other & 94 \\
\hline & & & & NS & NS & Hybrid & 160 \\
\hline & & Single/Multi & Infinite & NG/ST & $(\mathrm{R}, \mathrm{s}, \mathrm{S}) /(\mathrm{S}-1, \mathrm{~S})$ & MH \& Hybrid & 66 \\
\hline & Dual & Single & Infinite & $\mathrm{DT} \rightarrow \mathrm{DT}$ & other $\rightarrow$ other & $\mathrm{MH}$ & 123 \\
\hline & Multi & Single & Infinite & $\mathrm{DT} \rightarrow$ & $(\mathrm{S}-1, \mathrm{~S}) \rightarrow$ & $\mathrm{MH}$ & 91 \\
\hline & & & & $\cdots \mathrm{DT}$ & $\cdots(\mathrm{S}-1, \mathrm{~S})$ & & \\
\hline & & Multi & Infinite & $\mathrm{ST} \rightarrow$ & $(\mathrm{S}-1, \mathrm{~S}) \rightarrow$ & MM \& STA & 143 \\
\hline & & & & $\cdots \mathrm{ST}$ & $\cdots(\mathrm{S}-1, \mathrm{~S})$ & & \\
\hline
\end{tabular}

*Note: The entries with asterisk are stochastically constrained. 
Table 9: Details of transshipment papers

\begin{tabular}{|c|c|c|c|c|c|c|}
\hline Type & Pooling & $\begin{array}{c}\text { Number of } \\
\text { depots }\end{array}$ & $\begin{array}{l}\text { Non-identical } \\
\text { depots }\end{array}$ & $\begin{array}{c}\text { Transshipment } \\
\text { lead time }\end{array}$ & Ordering cost & References \\
\hline \multirow{2}{*}{ Preventive } & Partial & $\mathrm{N}$ & $\checkmark$ & $\checkmark$ & $\checkmark$ & 43 \\
\hline & complete & 2 & $\checkmark$ & $\checkmark$ & $\checkmark$ & 161 \\
\hline \multirow{7}{*}{ Emergency } & \multirow{3}{*}{ Partial } & $\mathrm{N}$ & & & & 23 \\
\hline & & $\mathrm{N}$ & $\checkmark$ & & & 106 \\
\hline & & $\mathrm{N}$ & $\checkmark$ & $\checkmark$ & $\checkmark$ & 65 \\
\hline & \multirow{4}{*}{ Complete } & $\mathrm{N}$ & & & & 23 \\
\hline & & $\mathrm{N}$ & $\checkmark$ & & & $63,107,162$ \\
\hline & & 2 & & & $\checkmark$ & 137 \\
\hline & & $\mathrm{N}$ & $\checkmark$ & $\checkmark$ & $\checkmark$ & 65,141 \\
\hline
\end{tabular}

maintenance actions reflect the condition of the machine (which implies condition monitoring is necessary) [71]. Although the combination of spare parts and transshipment problems is relevant (given the high cost associated with spare parts stock-out, the ability to transship spare parts from other locations with short lead times often is highly valuable), only Van Utterbeeck et al. [141] study this problem. As shown in Table 10, condition-based preventive maintenance has been studied relatively rarely.

Table 10: Details of spare parts inventory management articles

\begin{tabular}{lccc}
\hline Maintenance & Repairable items & Multi-item & References \\
\hline Corrective & $\checkmark$ & 121,141 \\
& $\checkmark$ & $\checkmark$ & 69,144 \\
Time-based preventive & & $\checkmark$ & 121 \\
& $\checkmark$ & $\checkmark$ & 69,100 \\
\hline Condition-based preventive & $\checkmark$ & & 144 \\
\hline
\end{tabular}

*Note: The entries with asterisk are stochastically constrained.

Tables 6 and 7 reveal that, surprisingly, the inventory structures studied in domain focused papers in general remain relatively simple, with most of these articles assuming a single echelon and deterministic (or even negligible) lead times. In terms of optimization methods, metaheuristic, metamodel-based, and hybrid methods clearly dominate in domain focused papers (with stochastically constrained problems being studied almost exclusively by hybrid methods). 
Table 8 reveals the (limited) use of stochastic approximation and sample path optimization in the methodology focused papers; overall, metaheuristics, metamodelling, and hybrid methods are also most prevalent here. In these papers, metamodelling techniques are most often used to solve stochastically constrained settings. Some of the methodology focused articles have been particularly influential: e.g., [19], [66] and [42] have been cited in more than 100 papers. Many papers in Table 8 are related, either because they build on similar test problems or they extend on similar approaches. Chick and Inoue [41] extend the influential R\&S approach of Chick and Inoue [42] for dependent simulation outputs (in the presence of common random numbers). Several articles (e.g., [7, 22, 82, 83]) use an inventory setting similar to the (s, S) setting of [19]. Other popular test problems are the (R, s, S) problem of Fu and Healy [58] (see [35, 36, 73, 74, 154]; except [154], all these articles compare their sim-opt method with the hybrid method of [58] which is a combination of sample path optimization and stochastic approximation) and the (R, s, S) problem presented in Koenig and Law [86] (see [34, 41, 42, 66, 111]). Xu et al. [155] modify the well-known sim-opt method of Hong and Nelson [66] (known as COMPASS) and show that their technique is more efficient for high dimensional problems. Lejeune and Margot [94] use the assemble-to-order problem of Hong and Nelson [66] to test their sim-opt technique.

Finally, we noticed a disconnect between domain and methodology focused articles: in spite of the powerful and successful sim-opt methods developed in articles such as $[19,66]$, most of the domain focused contributions rely on their own method for solving the inventory problem at hand (e.g., Herer et al. [63] combine sample path optimization and stochastic approximation to solve their transshipment problem and use this method in two subsequent articles, $[106,162])$.

\section{Categorization based on sim-opt method}

Table 11 categorizes the articles according to the simulation optimization method, and whether the replenishment decision variables are discrete (DI) versus continuous (CO). Articles that compare different sim-opt methods $[35,36,66,73,74,76,82,83,85,90,91,124,131,132,133$, $134,143,146,152,159]$ appear at multiple instances in the table. Those that combine different sim-opt techniques are hybrid methods. Some articles, such as [152] and [124] both compare and combine sim-opt methods.

Table 11 reveals that metaheuristic methods are by far the most popular simulation optimization technique, followed by hybrid approaches. Genetic algorithms are the most widely 
employed metaheuristic method. As Andradóttir [5] explains, genetic algorithms (and evolutionary algorithms in general) are "readily adaptable to simulation optimization" because of their ability to handle the simulation noise. Genetic algorithms also appear frequently in the comparison of different sim-opt methods (7 out of 20 papers: [90, 91, 131, 132, 133, 146, 159]), which underscores their importance. Moreover, they have been employed to address almost all of the inventory topics in Table 6. NSGA-II, which is a variant of genetic algorithms for multi-objective problems, appears in $[48,123]$. Particle swarm optimization shows up as another popular evolutionary method. Due to the high variety of metaheuristic methods, the $\mathrm{MH}-\mathrm{O}$ category contains many entries. As evident from Table 11, the commercial optimizer OPTQUEST (http://www.opttek.com/OptQuest), which combines tabu search, scatter search, and neural networks (see [92]) is relatively popular among the hybrid techniques. OPTQUEST is the only commercial optimizer encountered in this survey. Unlike the other hybrid methods, the exact details of the OPTQUEST algorithm have not been published [83]. Nevertheless, its seamless integration into many popular simulation software packages (e.g., ARENA, Simul8, and SIMIO), along with its user-friendly interface and powerful capabilities (e.g., to handle stochastic constraints and/or multi-objective optimization), make OPTQUEST a popular tool not only in domain-focused articles, but also in methodology-focused articles (see e.g., [82, 83]) where it is commonly used as a benchmark tool.

Table 11 shows that metamodel-based methods are also relatively common, in particular in methodology focused contributions. Furthermore, RSM is the most popular metamodelbased method, adopted in several domain focused papers; in contrast, kriging only has arisen in methodology focused papers thus far. Some authors have recently extended deterministic kriging to explicitly account for the noise in the outcomes of stochastic simulation (e.g., $[10,157])$; this extension has been employed only once in [116].

Gradient-based approaches have been used in several articles: stochastic approximation is mainly employed in methodology focused and older contributions ( 8 out of 11 articles that use stochastic approximation are older than 2007) while sample path optimization has been used mostly in domain focused papers, though usually as a component in hybrid methods. Ranking and Selection mostly appears as a component in hybrid methods, and it is almost exclusively employed by methodology focused articles. Multiple comparisons are rare; ordinal optimization has not been employed at all. As is evident from Table 11, continuous sim-opt techniques have been employed at times for the discrete case, whether by assuming the decision variables 
are continuous and rounding the final solution to get integer values (e.g., $[13,31,85])$ or by modifying the continuous simulation optimization technique (e.g., [82, 99, 139]).

Finally, Table 11 confirms that stochastically constrained problems are often solved using metamodel-based methods or hybrid techniques (in particular OPTQUEST). Kleijnen et al. [82], Kleijnen and Wan [83], and Wong et al. [152] compare the performance of several sim-opt methods for solving such problems.

A limited number of contributions (see Table 12) employed robust simulation optimization, implying that they seek solutions that are robust to the uncertainties inherent in stochastic simulation [46]. Although different types of uncertainties may exist (see [26, 46]), almost all of the articles in Table 12 focus on parameter uncertainty, implying that the decision maker is unsure about the main parameters that influence the inventory system (e.g., the demand rate). The only exception is $\mathrm{Xu}$ and Albin [154], which consider the uncertainty in the estimated coefficients of the fitted metamodel.

In general, robust simulation optimization techniques rely on two main approaches: we refer to the first approach as the worst case approach and the second approach is known as meanvariance trade-off approach. In a minimization problem, the worst-case approach first tries to find the value of the stochastic parameters that corresponds to the worst performance (i.e., it maximizes the performance with respect to the stochastic parameters). Then it minimizes the obtained maximum in terms of the decision variables (for a novel solution method, see [25]). The mean-variance trade-off approach accounts for the variance of the objective function when minimizing the mean in Equation (2) [46]. For example, it might entail combining the mean and variance of the performance measure into a single measure (which then can be optimized to find robust solutions). An example of this approach is the Taguchi method, which combines the mean and variance of the performance measure into the signal to noise ratio (SNR) [46]. Alternatively, the mean and variance of the simulation outcome can be considered separately, which is referred to as the dual response surface approach. Usually, the mean would be minimized, with the requirement that the variance must be below some threshold (e.g., [45]), or else both the mean and the variance are included in the objective of the minimization problem (e.g., [102]).

Table 12 reveals that though the dual response surface approach has received more attention than other techniques, it has been employed only in methodology focused papers. Miranda and del Castillo [102] extend the SPSA of [127] to obtain a robust solution. Dellino et al. [44] use RSM to minimize the mean of a cost function, while also requiring its variance to be smaller 
Table 11: Categorization of reviewed articles, based on the simulation optimization method and type of decision variables

\begin{tabular}{|c|c|c|c|c|c|}
\hline Method & Type & & $\begin{array}{l}\text { Decision } \\
\text { variables }\end{array}$ & Methodology focused & Domain focused \\
\hline \multirow{7}{*}{$\begin{array}{l}\text { MH } \\
(41)\end{array}$} & \multirow{2}{*}{\multicolumn{2}{|c|}{ GA }} & DI & 91,123 & $43,48,69,72,84,89,100,131,132,133,144$ \\
\hline & & & $\mathrm{CO}$ & 90 & $65,97,126,129,146,159$ \\
\hline & \multirow{2}{*}{\multicolumn{2}{|c|}{$\mathrm{PSO}$}} & DI & & $85,101,131,132,133,134$ \\
\hline & & & $\mathrm{CO}$ & & 146 \\
\hline & SA & & DI & $2,66,91,151$ & 131 \\
\hline & \multirow{2}{*}{\multicolumn{2}{|c|}{$\mathrm{MH}-\mathrm{O}$}} & DI & $22,66,91,98,155$ & $37,50,62,85,88,131,133,134,141$ \\
\hline & & & $\mathrm{CO}$ & $35,36,90$ & $38,39,76,140,159,164$ \\
\hline \multirow{8}{*}{$\begin{array}{l}\text { MM } \\
(16)\end{array}$} & \multirow{2}{*}{\multicolumn{2}{|c|}{ NN }} & DI & & 23 \\
\hline & & & $\mathrm{CO}$ & $32^{*}$ & \\
\hline & \multirow{2}{*}{\multicolumn{2}{|c|}{ RSM }} & DI & & 31 \\
\hline & & & $\mathrm{CO}$ & $7^{*}, 44^{*}, 61,83^{*}, 154$ & $24,122,124,152^{*}$ \\
\hline & \multirow{2}{*}{\multicolumn{2}{|c|}{$\mathrm{KR}$}} & DI & $82^{*}$ & \\
\hline & & & $\mathrm{CO}$ & $45^{*}$ & \\
\hline & \multirow{2}{*}{\multicolumn{2}{|c|}{ MM-O }} & DI & & 13 \\
\hline & & & $\mathrm{CO}$ & $32^{*}, 143$ & \\
\hline \multirow{2}{*}{ STA (11) } & & & DI & 99 & \\
\hline & & & $\mathrm{CO}$ & $19^{*}, 73,74,83^{*}, 102,143$ & $11,30,75,117$ \\
\hline SPO (2) & & & $\mathrm{CO}$ & 93 & 51 \\
\hline $\mathrm{R} \& \mathrm{~S}(4)$ & & & DI & $33,34,41,42$ & \\
\hline $\mathrm{MC}(4)$ & & & DI & & $14,112,113,120$ \\
\hline \multirow{2}{*}{ Other (9) } & & & DI & 94 & 29,121 \\
\hline & & & $\mathrm{CO}$ & 118 & $87,115,142,145,153$ \\
\hline \multirow{13}{*}{$\begin{array}{l}\text { Hybrid } \\
(27)\end{array}$} & \multirow{2}{*}{ OPTQUEST } & & DI & $66,82^{*}$ & $12,15^{*}, 161,163$ \\
\hline & & & $\mathrm{CO}$ & $83^{*}$ & $21^{*}, 76,137$ \\
\hline & \multirow{4}{*}{$\mathrm{SPO}$} & MH-O & DI & & $49^{*}$ \\
\hline & & MH-O & $\mathrm{CO}$ & & 107 \\
\hline & & STA & $\mathrm{CO}$ & $35,36,73,74$ & $63,106,162$ \\
\hline & & $\mathrm{R} \& \mathrm{~S}$ & DI & & $139^{*}$ \\
\hline & \multirow{5}{*}{$\mathrm{R} \& \mathrm{~S}$} & $\mathrm{SA}+\mathrm{MH}-\mathrm{O}$ & DI & & 47 \\
\hline & & SA & DI & 1 & \\
\hline & & NP & DI & 160 & \\
\hline & & $\mathrm{KR}$ & $\mathrm{CO}$ & 116 & \\
\hline & & MH-O & DI & 111 & \\
\hline & NN & $\mathrm{RSM}+\mathrm{MH}-\mathrm{O}$ & $\mathrm{CO}$ & & $152^{*}$ \\
\hline & MM-O & MH-O & $\mathrm{CO}$ & & 124 \\
\hline
\end{tabular}

*Note: Stochastically constrained papers are denoted by asterisk.

The numbers in the first column reflect the number of articles that applied the corresponding method. 
Table 12: Articles that employ robust simulation optimization

\begin{tabular}{lcc}
\hline Approach & Methodology focused & Domain focused \\
\hline Worst case & & 97 \\
Taguchi & & 122,124 \\
Dual Response & $44^{*}, 45^{*}, 102$ \\
Other & $7^{*}, 154$ & 38 \\
\hline
\end{tabular}

*Note: Entries with asterisk have stochastic constraints.

than a threshold; therefore, their work also belongs to the set of stochastically constrained articles. Dellino et al. [45] take a similar approach but instead of RSM, they use kriging. These two articles have two important limitations: (1) they do not take the randomness of stochastic simulation into account but just focus on parameter uncertainty in deterministic simulation; a limitation that is relaxed in [7], and (2) they use variance as a measure of robustness, which is criticized by several authors (e.g., [7, 158]). Angün [7] also extends Dellino et al. [44] by using average value at risk instead of variance and incorporating this measure into the objective function. Cheng et al. [38] take a similar approach but they use the expected downside risk as a robustness measure. Finally, despite the limitations of the Taguchi method (see [46]), Table 12 reveals that this method appears in two recent domain focused articles. It is worth mentioning that most of the robust contributions (6 out of 9 ) employ metamodel-based approaches.

\section{Conclusions and opportunities for research}

In this paper, we have reviewed and categorized the articles published between 1998 and 2013 that used simulation optimization to solve inventory replenishment problems. We have shown that this approach has become increasingly popular in domain focused articles; in different fields within inventory management (such as transshipment and spare parts inventory management), researchers have started using simulation optimization to solve practical problems that, without simplifying assumptions, are far too complex for analytical techniques. In spite of this, we found (somewhat surprisingly) that most of the solved inventory problems continue to be based on relatively simple supply chain structures consisting of a single echelon, often with deterministic (or even negligible) lead times. Since multi-echelon problems with stochastic lead times are common in practice, this gap indicates an attractive area for further research.

Metaheuristic methods and especially genetic algorithms are the most popular simulation 
optimization methods. Genetic algorithms are perhaps the most mature metaheuristic methods for simulation optimization in inventory management; they have been applied to different types of inventory management problems and often are compared with other sim-opt methods in terms of their performance. Metamodel-based methods appear less popular than metaheuristic or hybrid methods though, such that they appear mainly in methodology focused texts. Yet they also offer powerful means for solving robust sim-opt and stochastically constrained inventory problems. Applying metamodel-based methods (especially kriging, as stochastic kriging opens new opportunities to account for simulation noise) to practical inventory problems can be a promising area for research.

Stochastically constrained problems also remain relatively unstudied, in particular in domain focused articles. A final promising area for research is robust simulation optimization. Realizing the limitations of the Taguchi method, new robust sim-opt techniques have been recently developed, but most of them have been tested only in theoretical settings thus far. Applying these new techniques to more practical problems, and comparing their performance, is an interesting area for additional research.

\section{Acknowledgments}

This research was supported by the Research Foundation-Flanders (FWO)(grant no. G.0822.12). The authors also thank the two department editors and the anonymous referees for their useful comments.

\section{References}

[1] Ahmed, M. A. and Alkhamis, T. M. (2002). Simulation-based optimization using simulated annealing with ranking and selection. Computers \& Operations Research, 29:387-402.

[2] Alrefaei, M. H. and Diabat, A. H. (2009). A simulated annealing technique for multi-objective simulation optimization. Applied Mathematics and Computation, 215:3029-3035.

[3] Andradóttir, S. (1996). A scaled stochastic approximation algorithm. Management Science, 42:475-498.

[4] Andradóttir, S. (1998). Simulation optimization. In Handbook of Simulation: Principles, Methodology, Advances, Applications, and Practice, pages 307-333, New York, USA. John Wiley \& Sons.

[5] Andradóttir, S. (2006). An overview of simulation optimization via random search. In Handbooks in Operations Research and Management Science, volume 13, pages 617-631, North Holland. Elsevier.

[6] Andradóttir, S. and Prudius, A. A. (2010). Adaptive random search for continuous simulation optimization. Naval Research Logistics, 57:583-604. 
[7] Angün, E. (2011). A risk-averse approach to simulation optimization with multiple responses. Simulation Modeling Practice and Theory, 19:911-923.

[8] Angün, E. and Kleijnen, J. P. C. (2012). An asymptotic test of optimality conditions in multiresponse simulation optimization. INFORMS Journal on Computing, 24:53-65.

[9] Angün, E., Kleijnen, J. P. C., den Hertog, D., and Gürkan, G. (2009). Response surface methodology with stochastic constraints for expensive simulation. Journal of the Operational Research Society, 60:735-746.

[10] Ankenman, B., Nelson, B. L., and Staum, J. (2010). Stochastic kriging for simulation metamodeling. Operations Research, 58:371-382.

[11] Anupindi, R. and Tayur, S. (1998). Managing stochastic multiproduct systems: model, measures, and analysis. Operations Research, 46:S98-S111.

[12] Aras, N., Verter, V., and Boyaci, T. (2006). Coordination and priority decisions in hybrid manufacturing/remanufacturing systems. Production and Operations Management, 15:528-543.

[13] Arreola-Risa, A., Giménez-García, V. M., and Martínez-Parra, J. L. (2011). Optimizing stochastic productioninventory systems: A heuristic based on simulation and regression analysis. European Journal of Operational Research, 213:107-118.

[14] Atıcı, F. M., Lebedinsky, A., and Uysal, F. (2013). Inventory model of deteriorating items on non-periodic discrete time domains. European Journal of Operational Research, 230:284-289.

[15] Baker, T. and Jayaraman, V. (2012). Managing information and supplies inventory operations in a manufacturing environment. part 2: An order-timing and sizing algorithm. International Journal of Production Research, 50:1767-1779.

[16] Banks, J., Carson, J. S., Nelson, B. L., and Nicol, D. M. (2000). Discrete Event Systems Simulation. Prentice Hall, Englewood Cliffs, New Jersey, 3rd edition.

[17] Barton, R. R. (2009). Simulation optimization using metamodels. In Proceedings of the 2009 Winter Simulation Conference.

[18] Barton, R. R. and Meckesheimer, M. (2006). Metamodel-based simulation optimization. In Handbooks in Operations Research and Management Science, volume 13, pages 535-574, North Holland. Elsevier.

[19] Bashyam, S. and Fu, M. C. (1998). Optimization of $(\mathrm{s}, \mathrm{S})$ inventory systems with random lead times and a service level constraint. Management Science, 44:S243-S256.

[20] Batur, D. and Kim, S.-H. (2010). Finding feasible systems in the presence of constraints on multiple performance measures. ACM Transactions on Modeling and Computer Simulation, 47:800-816.

[21] Becerril-Arreola, R., Leng, M., and Parlar, M. (2013). Online retailers promotional pricing, free-shipping threshold, and inventory decisions: A simulation-based analysis. European Journal of Operational Research, 230:272-283.

[22] Bekker, J. and Aldrich, C. (2011). The cross-entropy method in multi-objective optimisation: An assessment. European Journal of Operational Research, 211:112-121.

[23] Bendoly, E. (2004). Integrated inventory pooling for firms servicing both on-line and store demand. Computers E Operations Research, 31:1465-1480. 
[24] Berthaut, F., Gharbi, A., and Pellerin, R. (2010). Joint hybrid repair and remanufacturing systems and supply control. International Journal of Production Research, 48:4101-4121.

[25] Bertsimas, D., Nohadani, O., and Teo, K. M. (2010). Robust optimization for unconstrained simulation-based problems. Operations Research, 58:161-178.

[26] Beyer, H.-G. and Sendhoff, B. (2007). Robust optimization a comprehensive survey. Computer Methods in Applied Mechanics and Engineering, 196:3190-3218.

[27] Bhatnagar, S., Hemachandra, N., and Mishra, V. K. (2011). Stochastic approximation algorithms for constrained optimization via simulation. ACM Transactions on Modeling and Computer Simulation, 21:15.

[28] Biles, W. E., Kleijnen, J. P. C., van Beers, W. C. M., and van Nieuwenhuyse, I. (2007). Kriging metamodeling in constrained simulation optimization: An explorative study. In Proceedings of the 2007 Winter Simulation Conference.

[29] Biswas, S. and Narahari, Y. (2004). Object oriented modeling and decision support for supply chains. European Journal of Operational Research, 153:704-726.

[30] Bollapragada, R. and Rao, U. S. (2006). Replenishment planning in discrete-time, capacitated, non-stationary, stochastic inventory systems. IIE Transactions, 38:605-617.

[31] Bouslah, B., Gharbi, A., and Pellerin, R. (2013). Joint optimal lot sizing and production control policy in an unreliable and imperfect manufacturing system. International Journal of Production Economics, 144:143-156.

[32] Can, B. and Heavey, C. (2012). A comparison of genetic programming and artificial neural networks in metamodeling of discrete-event simulation models. Computers \& Operations Research, 39:424-436.

[33] Chen, C.-H., He, D., Fu, M., and Lee, L. H. (2008). Efficient simulation budget allocation for selecting an optimal subset. INFORMS Journal on Computing, 20:579-595.

[34] Chen, C.-H., Yücesan, E., Dai, L., and Chen, H.-C. (2009). Optimal budget allocation for discrete-event simulation experiments. IIE Transactions, 42:60-70.

[35] Chen, S.-P. (2003). Simulation response optimization via an alternating variable method. Engineering Optimization, $35: 675-684$.

[36] Chen, S.-P. (2004). An alternating variable method with varying replications for simulation response optimization. Computers \& Mathematics with Applications, 48:769-778.

[37] Chen, Y., Pekny, J. F., and Reklaitis, G. V. (2013). Integrated planning and optimization of clinical trial supply chain system with risk pooling. Industrial \& Engineering Chemistry Research, 52:152-165.

[38] Cheng, L., Subrahmanian, E., and Westerberg, A. W. (2004). Multi-objective decisions on capacity planning and production-inventory control under uncertainty. Industrial \& Engineering Chemistry Research, 43:2192-2208.

[39] Chew, E. P., Hay Lee, L., Teng, S., and Hwee Koh, C. (2009). Differentiated service inventory optimization using nested partitions and MOCBA. Computers \& Operations Research, 36:1703-1710.

[40] Chick, S. E. (2006). Subjective probability and bayesian methodology. Handbooks in Operations Research and Management Science, 13:225-257.

[41] Chick, S. E. and Inoue, K. (2001a). New procedures to select the best simulated system using common random numbers. Management Science, 47:1133-1149. 
[42] Chick, S. E. and Inoue, K. (2001b). New two-stage and sequential procedures for selecting the best simulated system. Operations Research, 49:732-743.

[43] Dang, Q.-V., Yun, W.-Y., and Kopfer, H. (2012). Positioning empty containers under dependent demand process. Computers $8 \mathcal{G}$ Industrial Engineering, 62:708-715.

[44] Dellino, G., Kleijnen, J. P. C., and Meloni, C. (2010). Robust optimization in simulation: Taguchi and response surface methodology. International Journal of Production Economics, 125:52-59.

[45] Dellino, G., Kleijnen, J. P. C., and Meloni, C. (2012a). Robust optimization in simulation: Taguchi and krige combined. INFORMS Journal on Computing, 24:471-484.

[46] Dellino, G., Kleijnen, J. P. C., and Meloni, C. (2012b). Robust optimization in simulation: Taguchi and krige combined (online supplement). INFORMS Journal on Computing, 24:471-484.

[47] Diaz, R. and Bailey, M. (2011). Building knowledge to improve enterprise performance from inventory simulation models. International Journal of Production Economics, 134:108-113.

[48] Ding, H., Benyoucef, L., and Xie, X. (2009). Stochastic multi-objective production-distribution network design using simulation-based optimization. International Journal of Production Research, 47:479-505.

[49] Duan, Q. and Liao, T. W. (2013a). A new age-based replenishment policy for supply chain inventory optimization of highly perishable products. International Journal of Production Economics, 145:658-671.

[50] Duan, Q. and Liao, T. W. (2013b). Optimization of replenishment policies for decentralized and centralized capacitated supply chains under various demands. International Journal of Production Economics, 142:194-204.

[51] Feng, K., Rao, U. S., and Raturi, A. (2011). Setting planned orders in master production scheduling under demand uncertainty. International Journal of Production Research, 49:4007-4025.

[52] Fu, M. C. (1994a). Optimization via simulation: A review. Annals of Operations Research, 51:199-248.

[53] Fu, M. C. (1994b). Sample path derivatives for (s,S) inventory systems. Operations Research, 42:351-364.

[54] Fu, M. C. (2002). Optimization for simulation: theory vs. practice. INFORMS Journal on Computing, 14:192-215.

[55] Fu, M. C. (2006). Gradient estimation. In Handbooks in Operations Research and Management Science, volume 13, pages 575-616, North Holland. Elsevier.

[56] Fu, M. C. (2014). Handbook of simulation optimization.

[57] Fu, M. C., Glover, F. W., and April, J. (2005). Simulation optimization: A review, new developments, and applications. In Proceedings of the 2005 Winter Simulation Conference.

[58] Fu, M. C. and Healy, K. J. (1997). Techniques for optimization via simulation: an experimental study on an (s, s) inventory system. IIE Transactions, 29:191-199.

[59] FU, M. C. and Hill, D. (1997). Optimization of discrete event systems via simultaneous perturbation stochastic approximation. IIE Transactions, 29:233-243.

[60] Goldsman, D. and Nelson, B. L. (1998). Statistical screening, selection, and multiple comparison procedures in computer simulation. In Proceedings of the 1998 Winter Simulation Conference. 
[61] Greenwood, A. G., Rees, L. P., and Siochi, F. C. (1998). An investigation of the behavior of simulation response surfaces. European Journal of Operational Research, 110:282-313.

[62] Haijema, R., van der Wal, J., and van Dijk, N. M. (2007). Blood platelet production: Optimization by dynamic programming and simulation. Computers $\&$ Operations Research, 34:760-779.

[63] Herer, Y. T., Tzur, M., and Yücesan, E. (2006). The multilocation transshipment problem. IIE Transactions, $38: 185-200$

[64] Ho, Y.-C. (1999). An explanation of ordinal optimization: Soft computing for hard problems. Information Sciences, 113:169-192.

[65] Hochmuth, C. A. and Köchel, P. (2012). How to order and transship in multi-location inventory systems: The simulation optimization approach. International Journal of Production Economics, 140:646-654.

[66] Hong, L. J. and Nelson, B. L. (2006). Discrete optimization via simulation using compass. Operations Research, 54:115-129.

[67] Hong, L. J. and Nelson, B. L. (2009). A brief introduction to optimization via simulation. In Proceedings of the 2009 Winter Simulation Conference.

[68] Hsu, J. C. and Nelson, B. L. (1988). Optimization over a finite number of system designs with one-stage sampling and multiple comparisons with the best. In Proceedings of the 1988 Winter Simulation Conference.

[69] Ilgin, M. A. and Tunali, S. (2007). Joint optimization of spare parts inventory and maintenance policies using genetic algorithms. The International Journal of Advanced Manufacturing Technology, 34:594-604.

[70] Jalali, H. and Van Nieuwenhuyse, I. (2013). Simulation optimization in inventory management: A survey of recent contributions. FEB Research Report KBI-1405.

[71] Jardine, A. K., Lin, D., and Banjevic, D. (2006). A review on machinery diagnostics and prognostics implementing condition-based maintenance. Mechanical Systems and Signal Processing, 20:1483-1510.

[72] Kämpf, M. and Köchel, P. (2006). Simulation-based sequencing and lot size optimisation for a production-andinventory system with multiple items. International Journal of Production Economics, 104:191-200.

[73] Kao, C. and Chen, S.-P. (2006). A stochastic quasi-newton method for simulation response optimization. European Journal of Operational Research, 173:30-46.

[74] Kao, C., Li, C.-C., and Chen, S.-P. (2003). Simulation response optimization via direct conjugate direction method. Computers $\&$ Operations Research, 30:541-552.

[75] Kapuściński, R. and Tayur, S. (1998). A capacitated production-inventory model with periodic demand. Operations Research, 46:899-911.

[76] Keskin, B. B., Melouk, S. H., and Meyer, I. L. (2010). A simulation-optimization approach for integrated sourcing and inventory decisions. Computers $\&$ Operations Research, 37:1648-1661.

[77] Kim, S. and Henderson, S. G. (2008). The mathematics of continuous-variable simulation optimization. In Proceedings of the 2008 Winter Simulation Conference.

[78] Kim, S., Pasupathy, R., and Henderson, S. G. (2014). A guide to sample-average approximation. In Handbook of Simulation Optimization, chapter 8. Springer. 
[79] Kim, S.-H. and Nelson, B. L. (2006). Selecting the best system. In Handbooks in Operations Research and Management Science, volume 13, pages 501-534, North Holland. Elsevier.

[80] Kleijnen, J. P. C. (2008a). Design and Analysis of Simulation Experiments. Springer, New York.

[81] Kleijnen, J. P. C. (2008b). Response surface methodology for constrained simulation optimization. Simulation Modelling Practice and Theory, 16:50-64.

[82] Kleijnen, J. P. C., van Beers, W., and van Nieuwenhuyse, I. (2010). Constrained optimization in expensive simulation: Novel approach. European Journal of Operational Research, 202:164-174.

[83] Kleijnen, J. P. C. and Wan, J. (2007). Optimization of simulated systems: OptQuest and alternatives. Simulation Modelling Practice and Theory, 15:354-362.

[84] Köchel, P. and Nieländer, U. (2005). Simulation-based optimisation of multi-echelon inventory systems. International Journal of Production Economics, 93:505-513.

[85] Köchel, P. and Thiem, S. (2011). Search for good policies in a single-warehouse, multi-retailer system by particle swarm optimisation. International Journal of Production Economics, 133:319-325.

[86] Koenig, L. W. and Law, A. M. (1985). A procedure for selecting a subset of size $m$ containing the $l$ best of $k$ independent normal populations, with applications to simulation. Communications in Statistics-Simulation and Computation, 14:719-734.

[87] Kofjač, D., Kljajić, M., and Rejec, V. (2009). The anticipative concept in warehouse optimization using simulation in an uncertain environment. European Journal of Operational Research, 193:660-669.

[88] Kostić, K. (2009). Inventory control as a discrete system control for the fixed-order quantity system. Applied Mathematical Modelling, 33:4201-4214.

[89] Koulouriotis, D. E., Xanthopoulos, A. S., and Tourassis, V. D. (2010). Simulation optimisation of pull control policies for serial manufacturing lines and assembly manufacturing systems using genetic algorithms. International Journal of Production Research, 48:2887-2912.

[90] Kuriger, G. W. and Hank Grant, F. (2011). A lexicographic nelder-mead simulation optimization method to solve multi-criteria problems. Computers $\&$ Industrial Engineering, 60:555-565.

[91] Lacksonen, T. (2001). Empirical comparison of search algorithms for discrete event simulation. Computers 6 Industrial Engineering, 40:133-148.

[92] Laguna, M. (1997). Metaheuristic optimization with evolver, genocop and optquest. In EURO/INFORMS Joint International Meeting, Plenaries and Tutorials, pages 141-150.

[93] Lee, L. H., Chew, E. P., and Manikam, P. (2006). A general framework on the simulation-based optimization under fixed computing budget. European Journal of Operational Research, 174:1828-1841.

[94] Lejeune, M. A. and Margot, F. (2011). Optimization for simulation: Lad accelerator. Annals of Operations Research, 188:285-305.

[95] Li, D., Lee, L. H., and Ho, Y. C. (2002). Constraint ordinal optimization. Information Sciences, 148:201-220.

[96] Li, J., Sava, A., and Xie, X. (2009). Simulation-based discrete optimization of stochastic discrete event systems subject to non closed-form constraints. IEEE Transactions on Automatic Control, 54:2900-2904. 
[97] Lim, S. (2013). A joint optimal pricing and order quantity model under parameter uncertainty and its practical implementation. Omega, 41:998-1007.

[98] Lopez-Garcia, L. and Posada-Bolivar, A. (1999). A simulator that uses tabu search to approach the optimal solution to stochastic inventory models. Computers \& Industrial Engineering, 37:215-218.

[99] Luo, Y. and Lim, E. (2013). Simulation-based optimization over discrete sets with noisy constraints. IIE Transactions, 45:699-715.

[100] Lynch, P., Adendorff, K., Yadavalli, V. S. S., and Adetunji, O. (2013). Optimal spares and preventive maintenance frequencies for constrained industrial systems. Computers \& Industrial Engineering, 65:378-387.

[101] Mahnam, M., Yadollahpour, M. R., Famil-Dardashti, V., and Hejazi, S. R. (2009). Supply chain modeling in uncertain environment with bi-objective approach. Computers \& Industrial Engineering, 56:1535-1544.

[102] Miranda, A. K. and del Castillo, E. (2011). Robust parameter design optimization of simulation experiments using stochastic perturbation methods. Journal of the Operational Research Society, 62:198-205.

[103] Nezhad, A. M. and Mahlooji, H. (2014). An artificial neural network meta-model for constrained simulation optimization. Journal of the Operational Research Society, 65:1232 - 1244.

[104] Ólafsson, S. (2006). Metaheuristics. In Handbooks in Operations Research and Management Science, volume 13, pages 633-654, North Holland. Elsevier.

[105] Ólafsson, S. and Kim, J. (2002). Simulation optimization. In Proceedings of the 2002 Winter Simulation Conference.

[106] Özdemir, D., Yücesan, E., and Herer, Y. T. (2006). Multi-location transshipment problem with capacitated transportation. European Journal of Operational Research, 175:602-621.

[107] Özdemir, D., Yücesan, E., and Herer, Y. T. (2013). Multi-location transshipment problem with capacitated production. European Journal of Operational Research, 226:425-435.

[108] Park, C. and Kim, S.-H. (2011). Handling stochastic constraints in discrete optimization via simulation. In Proceedings of the 2011 Winter Simulation Conference.

[109] Pasupathy, R. and Ghosh, S. (2013). Simulation optimization: A concise overview and implementation guide. In Topaloglu, H., editor, TutORials in Operations Research, chapter 7, pages 122-150. INFORMS.

[110] Paterson, C., Kiesmüller, G., Teunter, R., and Glazebrook, K. (2011). Inventory models with lateral transshipments: A review. European Journal of Operational Research, 210:125-136.

[111] Pichitlamken, J., Nelson, B. L., and Hong, L. J. (2006). A sequential procedure for neighborhood selection-of-the-best in optimization via simulation. European Journal of Operational Research, 173:283-298.

[112] Pirard, F., Iassinovski, S., and Riane, F. (2008). A generic scalable simulation model for strategic supply chain management with emphasis on production activities. International Journal of Computer Integrated Manufacturing, $21: 455-467$.

[113] Pirard, F., Iassinovski, S., and Riane, F. (2011). A simulation based approach for supply network control. International Journal of Production Research, 49:7205-7226.

[114] Porteus, E. L. (1990). Stochastic inventory theory. In Stochastic Models, volume 2 of Handbooks in Operations Research and Management Science, chapter 12. 
[115] Prestwich, S. D., Tarim, S. A., Rossi, R., and Hnich, B. (2012). A neuroevolutionary approach to stochastic inventory control in multi-echelon systems. International Journal of Production Research, 50:2150-2160.

[116] Quan, N., Yin, J., Ng, S. H., and Lee, L. H. (2013). Simulation optimization via kriging: a sequential search using expected improvement with computing budget constraints. IIE Transactions, 45:763-780.

[117] Rao, U. S., Swaminathan, J. M., and Zhang, J. (2004). Multi-product inventory planning with downward substitution, stochastic demand and setup costs. IIE Transactions, 36:59-71.

[118] Rees, L. P., Greenwood, A. G., and Siochi, F. C. (2002). A best-first search approach for determining starting regions in simulation optimization. IIE Transactions, 34:283-295.

[119] Royset, J. O. and Szechtman, R. (2013). Optimal budget allocation for sample average approximation. Operations Research, 61:762-776.

[120] Sarkar, S. and Shewchuk, J. P. (2013). Use of advance demand information in multi-stage production-inventory systems with multiple demand classes. International Journal of Production Research, 51:57-68.

[121] Sarker, R. and Haque, A. (2000). Optimization of maintenance and spare provisioning policy using simulation. Applied Mathematical Modelling, 24:751-760.

[122] Shang, J. S., Li, S., and Tadikamalla, P. (2004). Operational design of a supply chain system using the taguchi method, response surface methodology, simulation, and optimization. International Journal of Production Research, $42: 3823-3849$.

[123] Shin, K. H., Kwon, I.-H., Lee, J.-H., and Kim, C. O. (2010). Performance trajectory-based optimised supply chain dynamics. International Journal of Computer Integrated Manufacturing, 23:87-100.

[124] Shukla, S. K., Tiwari, M. K., Wan, H.-D., and Shankar, R. (2010). Optimization of the supply chain network: simulation, taguchi, and psychoclonal algorithm embedded approach. Computers \& Industrial Engineering, 58:29-39.

[125] Silver, E. A. (1981). Operations research in inventory management: A review and critique. Operations Research, 29:628-645.

[126] Sounderpandian, J., Prasad, S., and Madan, M. (2008). Supplies from developing countries: optimal order quantities under loss risks. Omega, 36:122-130.

[127] Spall, J. C. (1992). Multivariate stochastic approximation using a simultaneous perturbation gradient approximation. IEEE Transactions on Automatic control, 37:332-341.

[128] Spall, J. C. (2005). Introduction to stochastic search and optimization: estimation, simulation, and control, volume 65. John Wiley \& Sons.

[129] Sundar Raj, T. and Lakshminarayanan, S. (2008). Performance assessment/enhancement methodology for supply chains. Industrial \& Engineering Chemistry Research, 47:748-759.

[130] Swisher, J. R., Hyden, P. D., Jacobson, S. H., and Schruben, L. W. (2004). A survey of recent advances in discrete input parameter discrete-event simulation optimization. IIE Transactions, 36:591-600.

[131] Taleizadeh, A. A., Barzinpour, F., and Wee, H.-M. (2011a). Meta-heuristic algorithms for solving a fuzzy single-period problem. Mathematical and Computer Modelling, 54:1273-1285. 
[132] Taleizadeh, A. A., Niaki, S. T. A., and Meibodi, R. G. (2013a). Replenish-up-to multi-chance-constraint inventory control system under fuzzy random lost-sale and backordered quantities. Knowledge-Based Systems, 53:147-156.

[133] Taleizadeh, A. A., Niaki, S. T. A., and Nikousokhan, R. (2011b). Constraint multiproduct joint-replenishment inventory control problem using uncertain programming. Applied Soft Computing, 11:5143-5154.

[134] Taleizadeh, A. A., Niaki, S. T. A., and Wee, H.-M. (2013b). Joint single vendor-single buyer supply chain problem with stochastic demand and fuzzy lead-time. Knowledge-Based Systems, 48:1-9.

[135] Tekin, E. and Sabuncuoglu, I. (2004). Simulation optimization: A comprehensive review on theory and applications. IIE Transactions, 36:1067-1081.

[136] Thomas, D. J. and Griffin, P. M. (1996). Coordinated supply chain management. European Journal of Operational Research, 94:1-15.

[137] Tlili, M., Moalla, M., and Campagne, J.-P. (2012). The trans-shipment problem in a two-echelon, multi-location inventory system with lost sales. International Journal of Production Research, 50:3547-3559.

[138] Tsai, S. C. and Fu, S. Y. (2014). Genetic-algorithm-based simulation optimization considering a single stochastic constraint. European Journal of Operational Research, 236:113-125.

[139] Tsai, S. C. and Zheng, Y. X. (2013). A simulation optimization approach for a two-echelon inventory system with service level constraints. European Journal of Operational Research, 229:364-374.

[140] Vaagen, H., Wallace, S. W., and Kaut, M. (2011). Modelling consumer-directed substitution. International Journal of Production Economics, 134:388-397.

[141] Van Utterbeeck, F., Wong, H., Van Oudheusden, D., and Cattrysse, D. (2009). The effects of resupply flexibility on the design of service parts supply systems. Transportation Research Part E: Logistics and Transportation Review, $45: 72-85$.

[142] Veeraraghavan, S. and Scheller-Wolf, A. (2008). Now or later: A simple policy for effective dual sourcing in capacitated systems. Operations Research, 56:850-864.

[143] Wan, X., Pekny, J. F., and Reklaitis, G. V. (2005). Simulation-based optimization with surrogate modelsApplication to supply chain management. Computers ES Chemical Engineering, 29:1317-1328.

[144] Wang, L., Chu, J., and Mao, W. (2009). A condition-based replacement and spare provisioning policy for deteriorating systems with uncertain deterioration to failure. European Journal of Operational Research, 194:184-205.

[145] Wang, X. (2011). Continuous review inventory model with variable lead time in a fuzzy random environment. Expert Systems with Applications, 38:11715-11721.

[146] Wang, X., Tang, W., and Zhao, R. (2007). Random fuzzy EOQ model with imperfect quality items. Fuzzy Optimization and Decision Making, 6:139-153.

[147] Waters, D. (2004). Inventory control and management. John Wiley \& Sons, Chichester, 2nd edition.

[148] Wensing, T. (2011). Periodic Review Inventory Systems: Performance Analysis and Optimization of Inventory Systems Within Supply Chains, volume 651. Springer.

[149] Whitney, J. E., Solomon, L. I., and Hill, S. D. (2001). Constrained optimization over discrete sets via SPSA with application to non-separable resource allocation. In Proceedings of the 2001 Winter Simulation Conference. 
[150] Williams, B. D. and Tokar, T. (2008). A review of inventory management research in major logistics journals: Themes and future directions. International Journal of Logistics Management, The, 19:212-232.

[151] Willis, K. O. and Jones, D. F. (2008). Multi-objective simulation optimization through search heuristics and relational database analysis. Decision Support Systems, 46:277-286.

[152] Wong, J.-T., Su, C.-T., and Wang, C.-H. (2012). Stochastic dynamic lot-sizing problem using bi-level programming base on artificial intelligence techniques. Applied Mathematical Modelling, 36:2003-2016.

[153] Xie, X. (1998). Stability analysis and optimization of an inventory system with bounded orders. European Journal of Operational Research, 110:126-149.

[154] Xu, D. and Albin, S. L. (2003). Robust optimization of experimentally derived objective functions. IIE Transactions, 35:793-802.

[155] Xu, J., Nelson, B. L., and Hong, L. J. (2013). An adaptive hyperbox algorithm for high-dimensional discrete optimization via simulation problems. INFORMS Journal on Computing, 25:133-146.

[156] Yang, W.-N. and Nelson, B. L. (1991). Using common random numbers and control variates in multiple-comparison procedures. Operations Research, 39:583-591.

[157] Yin, J., Ng, S., and Ng, K. (2011). Kriging metamodel with modified nugget-effect: The heteroscedastic variance case. Computers \& Industrial Engineering, 61:760-777.

[158] Yin, Y., Madanat, S. M., and Lu, X.-Y. (2009). Robust improvement schemes for road networks under demand uncertainty. European Journal of Operational Research, 198:470-479.

[159] Yokoyama, M. (2002). Integrated optimization of inventory-distribution systems by random local search and a genetic algorithm. Computers \& Industrial Engineering, 42:175-188.

[160] Yoo, T., Cho, H., and Yücesan, E. (2010). Hybrid algorithm for discrete event simulation based supply chain optimization. Expert Systems with Applications, 37:2354-2361.

[161] Young Yun, W., Mi Lee, Y., and Seok Choi, Y. (2011). Optimal inventory control of empty containers in inland transportation system. International Journal of Production Economics, 133:451-457.

[162] Yücesan, E. and Gong, Y. (2012). Stochastic optimization for transshipment problems with positive replenishment lead times. International Journal of Production Economics, 135:61-72.

[163] Zanoni, S., Ferretti, I., and Tang, O. (2006). Cost performance and bullwhip effect in a hybrid manufacturing and remanufacturing system with different control policies. International Journal of Production Research, 44:3847-3862.

[164] Zeballos, A. C., Seifert, R. W., and Protopappa-Sieke, M. (2013). Single product, finite horizon, periodic review inventory model with working capital requirements and short-term debt. Computers E Operations Research, 40:29402949 .

[165] Zipkin, P. H. (2000). Foundations of inventory management, volume 2. McGraw-Hill New York. 